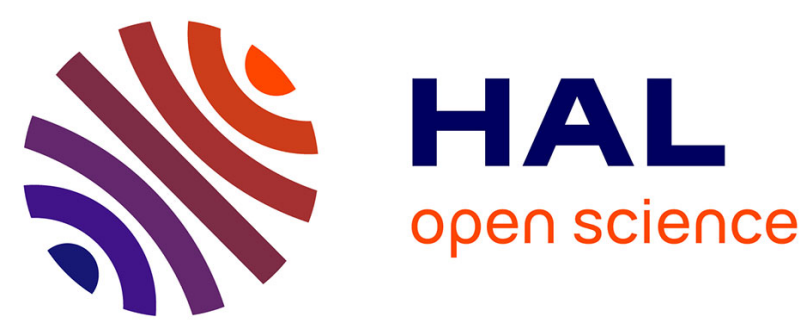

\title{
Quantitative Structural Constraints for Organic Powders at Natural Isotopic Abundance Using Dynamic Nuclear Polarization Solid-State NMR Spectroscopy Giulia Mollica, Myriam Dekhil, Fabio Ziarelli, Pierre Thureau, Stéphane Viel
}

\section{- To cite this version:}

Giulia Mollica, Myriam Dekhil, Fabio Ziarelli, Pierre Thureau, Stéphane Viel. Quantitative Structural Constraints for Organic Powders at Natural Isotopic Abundance Using Dynamic Nuclear Polarization Solid-State NMR Spectroscopy. Angewandte Chemie International Edition, 2015, 54 (45), pp.60286031. 10.1002/anie.201501172 . hal-01406490

\author{
HAL Id: hal-01406490 \\ https://hal.science/hal-01406490
}

Submitted on 15 Sep 2021

HAL is a multi-disciplinary open access archive for the deposit and dissemination of scientific research documents, whether they are published or not. The documents may come from teaching and research institutions in France or abroad, or from public or private research centers.
L'archive ouverte pluridisciplinaire HAL, est destinée au dépôt et à la diffusion de documents scientifiques de niveau recherche, publiés ou non, émanant des établissements d'enseignement et de recherche français ou étrangers, des laboratoires publics ou privés. 


\title{
Quantitative structural constraints for organic powders at natural abundance via dynamic nuclear polarization solid-state NMR ${ }^{* *}$
}

\author{
Giulia Mollica, Myriam Dekhil, Fabio Ziarelli, Pierre Thureau, ${ }^{\star}$ and Stéphane Viel ${ }^{\star}$
}

\begin{abstract}
A straightforward methodology is reported to quantitatively relate structural constraints based on ${ }^{13} \mathrm{C}-{ }^{13} \mathrm{C}$ double-quantum buildup curves obtained by dynamic nuclear polarization (DNP) solidstate NMR to the crystal structure of organic powders at natural isotopic abundance. This methodology relies on the tremendous gain in NMR sensitivity provided by DNP ( 50-fold here, which lowered the experimental time from a few years to a few days), and is sensitive to the molecular conformation and crystal packing of the studied powder sample (in this case theophylline). This allows crystal structures to be rapidly and effectively discriminated, and paves the way to three-dimensional structure elucidation of powders via the combination with powder $X$-ray diffraction, crystal prediction, and density functional theory computation of NMR chemical shifts.
\end{abstract}

Although single crystal X-ray diffraction (SCXRD) is currently unrivalled for the structural elucidation of organic compounds, it is typically inadequate when single crystals of sufficient size (or quality) are not available, and hence structure determination of microcrystalline powders remains highly challenging. In this context, NMR crystallography has emerged as a powerful technique by opening the way to ab initio structure determination of organic powders [1] Precisely, powder X-ray diffraction (PXRD) and crystal structure prediction methods ${ }^{[2]}$ can be combined to generate trial crystal structures that are refined using NMR experiments. One possible approach compares experimental chemical shifts with those computed by density functional theory (DFT) from a pool of trial crystal structures, the best match yielding the correct (or most likely) structure. However, because chemical shifts are not directly related to the crystal structure, their use as structural refinement constraints is not entirely satisfactory. In fact, ${ }^{13} \mathrm{C}$ chemical shifts were shown to be insufficiently sensitive for structure discrimination, whereas ${ }^{1} \mathrm{H}$ chemical shifts (which are sensitive to the crystal packing) showed limitations in case of reduced number of assigned resonances [1a] Accessing alternative structural constraints is therefore desirable. Contrary to liquid-state NMR, however,

[^] Dr. G. Mollica, M. Dekhil, Dr. P. Thureau, Prof. S. Viel

Aix-Marseille Université, CNRS, ICR (UMR 7273)

13397 Marseille cedex 20 (France)

E-mail: pierre.thureau@univ-amu.fr

Dr. F. Ziarelli s.viel@univ-amu.fr

Aix-Marseille Université, CNRS, Centrale Marseille Fédération des Sciences Chimiques de Marseille (FR 1739) 13397 Marseille cedex 20 (France)

$\left[{ }^{\star \star}\right]$ We would like to thank Bruker Biospin SAS for providing access to the DNP solid-state NMR spectrometer. We are also very grateful to Dr. O. Ouari and Prof. P. Tordo for providing the TEKPol biradical, and to Dr. F. Aussenac for his assistance with the DNP solid-state NMR experiments. This work has been carried out thanks to the support of the French National Research Agency (ANR), grant ANR-13-JS080001, and of the A*MIDEX project (n'ANR-11-IDEX-0001-02) funded by the "Investissements d'Avenir" French Government program and managed by the ANR.

Supporting information for this article is available on the WWW under http://dx.doi.org/ where such constraints can be derived by nuclear Overhauser effec [3] or residual dipolar couplind ${ }^{[4]}$ experiments, SSNMR still strives for similar experiments that could easily provide meaningful structural parameters. Studies on inorganic solids [5] indicate that dipolar couplings could be valuable candidates, but the high density of spins for abundant nuclei in organic compounds $\left({ }^{1} \mathrm{H}\right.$, or ${ }^{13} \mathrm{C}$ for uniformly enriched samples) drastically complicates the spin dynamics and prevents the measurement of long-range homonuclear spin couplings [6] Analyzing rare spins such as ${ }^{13} \mathrm{C}$ or ${ }^{15} \mathrm{~N}$ in natural abundance (NA) samples could alleviate this issue but the low NMR sensitivity precludes it. Recent work has shown, however, that SSNMR sensitivity of microcrystalline samples (with crystal widths ranging from 0.05 to $10 \mu \mathrm{m}$ ) could be enhanced by highfield low-temperature magic-angle spinning (MAS) dynamic nuclear polarization (DNP) [7] DNP relies on the microwavedriven transfer of the electron spin polarization to nuclei, giving a maximum NMR signal enhancement equal to the ratio of the electron to nuclear magnetogyric ratios $\left(\sim 660\right.$ for $\left.{ }^{1} \mathrm{H}\right)$. As a result, sensitivity enhancements of 1 to 2 orders of magnitude can now be envisaged [8] allowing two-dimensional (2D) dipolar and/or scalar correlation SSNMR experiments based on rare spins detection to be recorded on NA samples within reasonable times [n particular, DNP-enhanced 2D double-quantum (DQ) dipolar correlation experiments have been recently used to probe qualitatively 1-bond or 2-bond ${ }^{13} \mathrm{C}-{ }^{13} \mathrm{C}$ correlations in NA powders ( $v i a$ the comparison of cross-peak amplitudes obtained for specific mixing times) [7] [b] and to estimate the distance between ${ }^{29} \mathrm{Si}^{29} \mathrm{Si}$ sites on the surface of silica nanoparticles (via numerical simulations) [9] Overall, $2 \mathrm{D} \quad \mathrm{DQ}{ }^{13} \mathrm{C}-{ }^{13} \mathrm{C}$ dipolar correlation experiments, while extremely challenging for NA samples due to the low ${ }^{13} \mathrm{C}$ natural abundance $(1.1 \%)$, could provide significant constraints for structure determination of organic powders, but the required framework relating quantitatively ${ }^{13} \mathrm{C}-{ }^{13} \mathrm{C}$ cross-peak amplitudes to structural parameters has not been reported yet.

Here, we show how DNP-enhanced $2 \mathrm{D}{ }^{13} \mathrm{C}-{ }^{13} \mathrm{C} D Q$ dipolar correlation experiments can be used to straightforwardly obtain quantitative data that are sensitive to the crystal structure of NA organic powders. We focused on theophylline (Figure 1a) available as a NA powder. Theophylline is a pharmaceutical compound representative of the current challenges found in structure determination: it has several polymorphic forms ${ }^{[10]}$ and, although it may form crystals suitable for SCXRD, its crystallization is far from straightforward. Moreover, the abovementioned ab initio NMR crystallography approach based on ${ }^{1} \mathrm{H}$ chemical shifts refinement failed to determine its correct crystal structure Ha] Herein, the anhydrous polymorph of NA theophylline was incipiently wetted with a tetrabromoethane solution of the TEKPol biradica [11] (used as a source of electron spin polarization) and subsequently analyzed by DNP at $105 \mathrm{~K}$. We obtained a DNP signal enhancement of 12 and an overall sensitivity enhancement of $\sim 50$ (see the Supporting

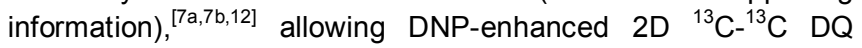
dipolar correlation spectra of NA theophylline to be recorded in 


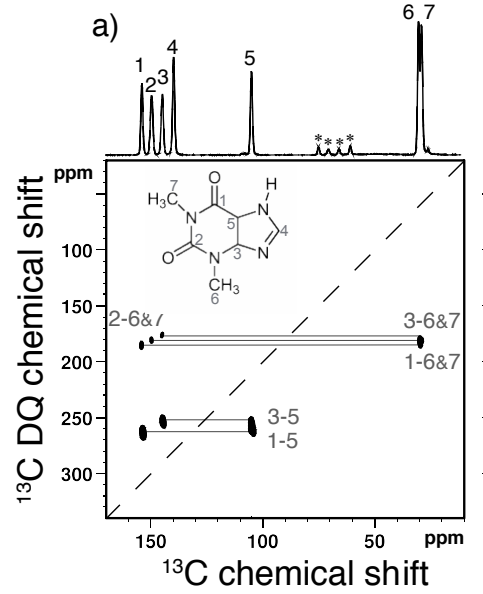

b)

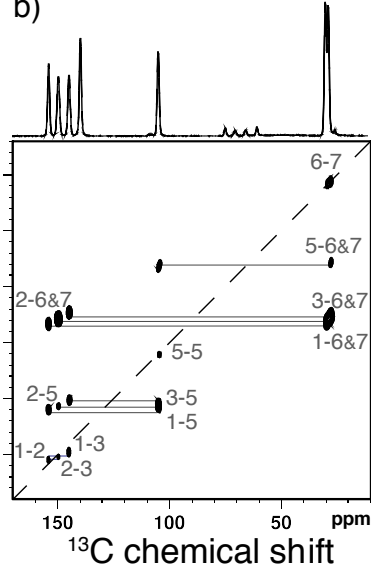

Figure 1. DNP-enhanced $2 \mathrm{D}{ }^{13} \mathrm{C}-{ }^{3} \mathrm{C} \mathrm{DQ}$ dipolar correlation spectra of the anhydrous polymorph of NA theophylline impregnated with a TEKPol tetrabromoethane solution. Correlations between pairs of ${ }^{13} \mathrm{C}$ resonances appear in the $D Q$ dimension at the sum of their chemical shifts. The DQ excitation time $\tau_{D Q}$ is 0.5 and $2 \mathrm{~ms}$ in a) and b), respectively, leading to the observation of correlation peaks between ${ }^{13} \mathrm{C}$ spins separated by short and longer distances, respectively. The ${ }^{13} \mathrm{C}$ CPMAS spectrum is shown in the top projections and has been assigned according to the theophylline molecular structure shown in the left inset (* denotes spinning side bands).

$\sim 7 \mathrm{~h}$ (instead of $\sim 2$ years at room temperature without DNP). Two such spectra with a short and a longer DQ excitation times $\left(\tau_{\mathrm{DQ}}\right)$ are respectively shown in Figure $1 \mathrm{a}$ and $1 \mathrm{~b}$. The strongest correlations in Figure 1a arise mainly from ${ }^{13} \mathrm{C}-{ }^{13} \mathrm{C}$ spin pairs separated by short distances (C1-C5, C3-C5), whereas weaker correlations due to ${ }^{13} \mathrm{C}-{ }^{13} \mathrm{C}$ spin pairs separated by longer distances (C5-C6\&C7, C5-C5) are observed in Figure $1 \mathrm{~b}$.

More quantitatively, the amplitudes of each pair of ${ }^{13} \mathrm{C}-{ }^{13} \mathrm{C}$ correlation peaks in a series of $2 \mathrm{D} \mathrm{DQ}$ dipolar correlation spectra were measured and plotted as a function of $\tau_{\mathrm{DQ}}$, yielding $\mathrm{DQ}$ build-up curves that were scaled to the ${ }^{13} \mathrm{C}$ CPMAS spectrum recorded under identical conditions (Figure 2). Due to the low ${ }^{13} \mathrm{C}$ natural abundance, the spin system only consists of isolated ${ }^{13} \mathrm{C}-{ }^{13} \mathrm{C}$ spin pairs. These data could thus be fitted with a straightforward analytical function based on the sum of the distinct ${ }^{13} \mathrm{C}-{ }^{13} \mathrm{C}$ dipolar couplings that contribute to the correlation peak under study. This differs considerably from the complex many-body spin dynamics observed in spin networks $\left({ }^{1} \mathrm{H}\right.$, or ${ }^{13} \mathrm{C}$ for uniformly enriched samples). Figure 2 shows the analytical function plotted for the internuclear distances taken from the reference crystal structure of anhydrous theophylline previously determined by SCXRD and deposited in the Cambridge Structural Database (CSD entry code: BAPLOT06) $\left.{ }^{[10 \mathrm{a}-\mathrm{c}]}\right]$ This analytical function was also multiplied by a constant to scale the data and by an exponential decay to account for magnetic relaxation (see the Supporting Information) ${ }^{[13]}$ The agreement between the experimental and the analytical ${ }^{13} \mathrm{C}-{ }^{13} \mathrm{C} \mathrm{DQ}$ build-up curves in Figure 2 is excellent, showing trends that are clearly different depending on the observed ${ }^{13} \mathrm{C}-{ }^{13} \mathrm{C} D Q$ correlation peak. Importantly, these curves could only be perfectly reproduced by considering both the molecular conformation and the crystal packing of the theophylline crystal structure, which influenced the nature (intravs. intermolecular) of the involved dipolar couplings. This

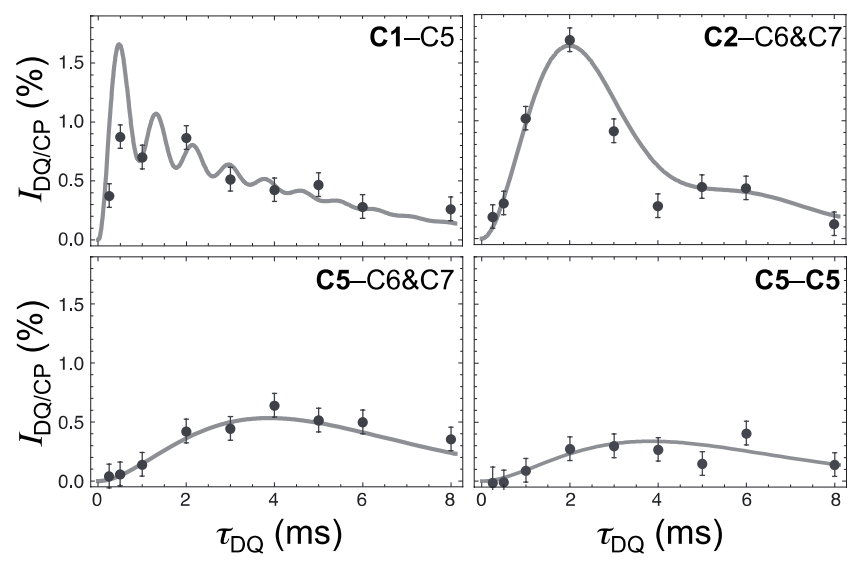

Figure 2. Double-quantum (DQ) build-up curves for selected pairs of ${ }^{13} \mathrm{C}$ dipolar correlation peaks shown by numbers on the top right of each graph (the bold number refers to the detected resonance). The experimental data points $(\bullet)$ were obtained by integrating the correlation peaks obtained in a series of DNP-enhanced 2D ${ }^{13} \mathrm{C}^{13} \mathrm{C} D Q$ correlation spectra (see Figure 1) recorded for distinct $D Q$ excitation time $\left(\tau_{D Q}\right)$ values. The solid lines represent an analytical function that considers the ${ }^{13} \mathrm{C}-{ }^{13} \mathrm{C}$ pairs involved in a specific correlation peak (see Supporting information for details and other curves).

confirmed that ${ }^{13} \mathrm{C}-{ }^{13} \mathrm{C} D Q$ dipolar build-up curves obtained by DNP-enhanced SSNMR provided meaningful quantitative data that were sensitive to the crystal structure of the powder sample under study. In fact, attempts to reproduce these curves with alternative (but highly similar) theophylline crystal structures proved unsuccessful.

First, the sensitivity of our methodology to molecular conformation was studied by considering, in place of the reference structure (BAPLOT06), a virtual crystal structure that purposely differed from the reference only by an all-carbon atoms root-mean-square-deviation ( $\mathrm{rmsd}$ ) of $15 \mathrm{pm}$, while exhibiting otherwise identical space group and unit cell parameters. An rmsd of $15 \mathrm{pm}$ is the precision that can be achieved with state-of-the-art NMR crystallography approaches based on chemical shift refinement ${ }^{[1]}$ Figure $3 a$ compares the $\mathrm{DQ}$ build-up curve obtained experimentally for the C2-C5 correlation peak with those calculated from the virtual and reference crystal structures. This comparison could be more suitably evaluated using the goodness-of-fit coefficient of the involved C2-C5 spin pair $\left(\chi_{2-5}^{2}\right)$, which was higher for the virtual (13.5) than for the reference (8.0) crystal structure. This confirmed that the $\mathrm{DQ}$ build-up curves, especially those involving medium-to-long range internuclear distances, could be used to detect small changes in molecular conformation (typical of conformational polymorphs). Second, the sensitivity to the crystal packing was studied by considering 3 different packing polymorphs of theophylline: the monoclinic [10d] the monohydrate ${ }^{[100]}$ and the high-temperature ${ }^{[10 \mathrm{~b}]}$ polymorphs (CDS entry codes: BAPLOT02, THEOPH02, and BAPLOT04, respectively). These polymorphs have almost identical molecular conformation but different unit-cell parameters. Moreover, BAPLOT02 and THEOPH02 have different space groups (P21/c and $\mathrm{P} 21 / \mathrm{n}$, respectively), whereas BAPLOT04 and BAPLOT06 have the same space group (Pna $\left.2_{1}\right)$. For these polymorphs, deviations between calculated and experimental $D Q$ build-up curves were observed for correlation peaks that primarily 

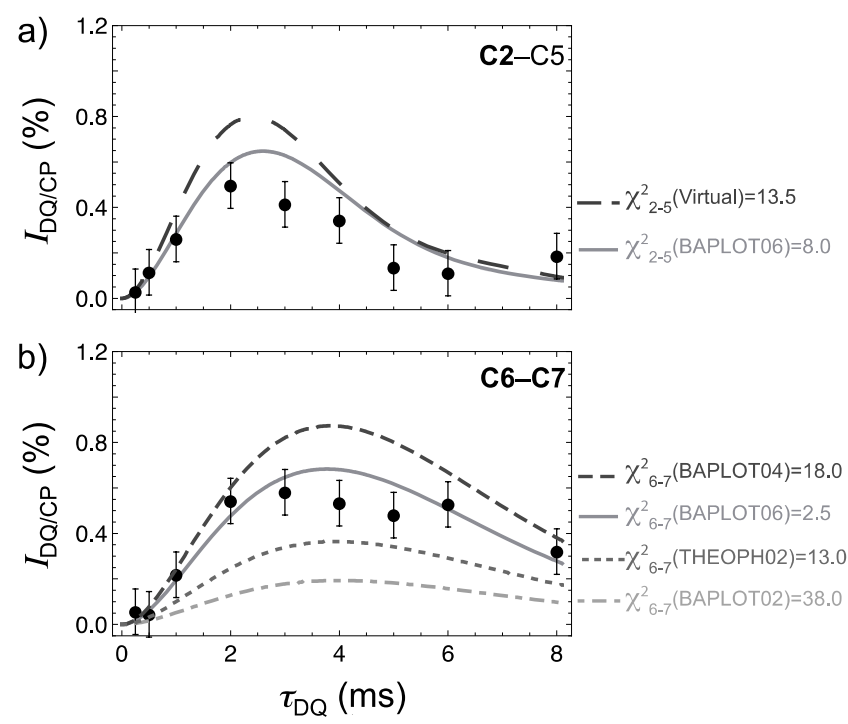

Figure 3. Sensitivity of the $D Q$ build-up curves to the theophylline crystal structure. In a) and b), the solid line is the analytical DQ build-up curve calculated for the reference structure (BAPLOT06). The agreement between the calculated and experimental curves for a given $i-j$ spin pair is evaluated

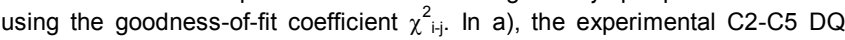
build-up curve is shown together with that calculated for a virtual structure only differing from the reference structure by an all-carbon atoms rmsd of $15 \mathrm{pm}$ (long-dashed curve). In b) the dot-dashed, dotted, and dashed curves are the analytical $\mathrm{C} 6-\mathrm{C} 7 \mathrm{DQ}$ build-up curves calculated for the monoclinic (BAPLOT02), monohydrate (THEOPH02), and high-temperature (BAPLOT04) packing theophylline polymorphs, respectively.

depend on intermolecular distances. This is shown in Figure $3 b$, where the analytical C6-C7 DQ build-up curves calculated for each theophylline polymorph are compared to the experimental data. The range of $\chi_{6-7}^{2}$ values clearly shows that this correlation is sensitive to the crystal packing of the polymorphs. A similar trend was observed for C5-C5 (data not shown). Overall, a global $\chi^{2}$ parameter including all ${ }^{13} \mathrm{C}-{ }^{13} \mathrm{C}$ spin pairs could be defined, which allowed these crystal structures to be sorted out and the reference crystal structure to be identified (Table 1).

In summary, we have shown that ${ }^{13} \mathrm{C}-{ }^{13} \mathrm{C} D Q$ dipolar build-up curves recorded by DNP-enhanced SSNMR on NA powders can be straightforwardly analyzed, providing quantitative data that are sensitive to the sample molecular conformation and crystal packing. This enables the rapid and effective discrimination of trial crystal structures of organic powders generated by NMR crystallography approaches, and will hence be highly valuable to existing PXRD, crystal prediction, and DFT-based chemical shift

Table 1: ${ }^{13} \mathrm{C}-{ }^{13} \mathrm{C}$ DQ build-up curves goodness-of-fit coefficients $\chi^{2}$ for different theophylline crystal structures (calculated using 8 distinct correlation peaks).

\begin{tabular}{lc}
\hline Theophylline crystal structures & Goodness-of-fit coefficient $\chi^{2}$ \\
\hline BAPLOT06 ${ }^{[a]}$ & 63.0 \\
Virtual structure $\left({ }^{13} \mathrm{C} \text { RMSD }=15 \mathrm{pm}\right)^{[\mathrm{b}]}$ & 84.0 \\
BAPLOT02 ${ }^{[\mathrm{c}]}$ & 98.0 \\
BAPLOT04 $^{[\mathrm{cc}]}$ & 94.0 \\
THEOPH02 $^{[\mathrm{c}]}$ & 79.0 \\
\hline
\end{tabular}

${ }^{[a]}$ Reference crystal structure determined by SCXRD. ${ }^{[b, c]}$ Trial crystal structures selected to study the sensitivity of our methodology to molecular conformation ${ }^{[\mathrm{b}]}$ and crystal packing ${ }^{[\mathrm{c}]}$. prediction methods for the tridimensional structure elucidation of organic powders at natural isotopic abundance.

Received: February $6^{\text {th }} 2015$

Keywords: solid-state NMR • dynamic nuclear polarization • crystal structure $\cdot$ natural abundance $\cdot$ organic solids

[1] a) M. Baias, C. M. Widdifield, J. N. Dumez, H. P. G. Thompson, T. G. Cooper, E. Salager, S. Bassil, R. S. Stein, A. Lesage, G. M. Day, L. Emsley, Phys. Chem. Chem. Phys. 2013, 15, 8069-8080; b) M. Baias, J.-N. Dumez, P. H. Svensson, S. Schantz, G. M. Day, L. Emsley, J. Am. Chem. Soc. 2013, 135, 17501-17507.

[2] S. L. Price, Acc. Chem. Res. 2009, 42, 117-126.

[3] D. Neuhaus, M. Williamson, The Nuclear Overhauser Effect in structural and conformational analysis, 2nd edition ed., John Wiley \& Sons, Ltd., Chichester, 2000.

[4] a) J. Emsley, in Encyclopedia of Nuclear Magnetic Resonance, Vol. 4 (Eds.: D. M. Grant, R. K. Harris), John Wiley \& Sons, Chichester, 1996; b) N. Tjandra, A. Bax, Science 1997, 278, 1111-1114; c) C. M. Thiele, A. Marx, R. Berger, J. Fischer, M. Biel, A. Giannis, Angew. Chem. Int. Ed. 2006, 45, 4455-4460; Angew. Chem. 2006, 118, 4566-4571; d) G. Kummerloewe, B. Crone, M. Kretschmer, S. F. Kirsch, B. Luy, Angew. Chem. Int. Ed. 2011, 50, 2643-2645; Angew. Chem. 2011, 123, 26932696.

[5] D. H. Brouwer, S. Cadars, J. Eckert, Z. Liu, O. Terasaki, B. F. Chmelka, J. Am. Chem. Soc. 2013, 135, 5641-5655.

[6] a) V. Ladizhansky, Solid State Nucl. Magn. Reson. 2009, 36, 119-128; b) G. De Paëpe, Annu. Rev. Phys. Chem. 2012, 63, 661-684; c) K. Saalwaechter, ChemPhysChem 2013, 14, 3000-3014.

[7] a) A. J. Rossini, A. Zagdoun, F. Hegner, M. Schwarzwalder, D. Gajan, C. Coperet, A. Lesage, L. Emsley, J. Am. Chem. Soc. 2012, 134, 16899-16908; b) H. Takahashi, D. Lee, L. Dubois, M. Bardet, S. Hediger, G. De Paëpe, Angew. Chem. Int. Ed. 2012, 51, 11766-11769; Angew. Chem. 2012, 124, 11936-11939; c) A. J. Rossini, C. M. Widdifield, A. Zagdoun, M. Lelli, M. Schwarzwälder, C. Copéret, A. Lesage, L. Emsley, J. Am. Chem. Soc. 2014, 136, 2324-2334.

[8] a) Q. Z. Ni, E. Daviso, T. V. Can, E. Markhasin, S. K. Jawla, T. M. Swager, R. J. Temkin, J. Herzfeld, R. G. Griffin, Acc. Chem. Res. 2013 46, 1933-1941; b) A. J. Rossini, A. Zagdoun, M. Lelli, A. Lesage, C. Copéret, L. Emsley, Acc. Chem. Res. 2013, 46, 1942-1951.

[9] D. Lee, G. Monin, D. Nghia Tuan, I. Z. Lopez, M. Bardet, V. Mareau, L. Gonon, G. De Paëpe, J. Am. Chem. Soc. 2014, 136, 13781-13788.

[10] a) Y. Ebisuzaki, P. D. Boyle, J. A. Smith, Acta. Crystallogr. C 1997, 53, 777-779; b) K. Fucke, G. J. McIntyre, C. Wilkinson, M. Henry, J. A. K Howard, J. W. Steed, Cryst Growth Des 2012, 12, 1395-1401; c) E. D. L. Smith, R. B. Hammond, M. J. Jones, K. J. Roberts, J. B. O. Mitchell, S. L. Price, R. K. Harris, D. C. Apperley, J. C. Cherryman, R. Docherty, J. Phys. Chem. B 2001, 105, 5818-5826; d) S. Zhang, A. Fischer, Acta. Crystallogr. E 2011, 67, O3357-U1293.

[11] A. Zagdoun, G. Casano, O. Ouari, M. Schwarzwälder, A. J. Rossini, F. Aussenac, M. Yulikov, G. Jeschke, C. Copéret, A. Lesage, P. Tordo, L. Emsley, J. Am. Chem. Soc. 2013, 135, 12790-12797.

[12] T. Kobayashi, O. Lafon, A. S. L. Thankamony, I. I. Slowing, K. Kandel, D. Carnevale, V. Vitzthum, H. Vezin, J. P. Amoureux, G. Bodenhausen, M. Pruski, Phys. Chem. Chem. Phys. 2013, 15, 5553-5562.

[13] D. H. Brouwer, P. E. Kristiansen, C. A. Fyfe, M. H. Levitt, J. Am. Chem. Soc. 2005, 127, 542-543. 
Entry for the Table of Contents

\section{COMMUNICATION}

Structure of organic powders: A straightforward methodology is reported to quantitatively relate structural constraints based on ${ }^{13} \mathrm{C}$ ${ }^{13} \mathrm{C}$ double-quantum build-up curves obtained by dynamic nuclear polarization solid-state NMR to the crystal structure of organic powders at natural isotopic abundance, as shown here with theophylline.

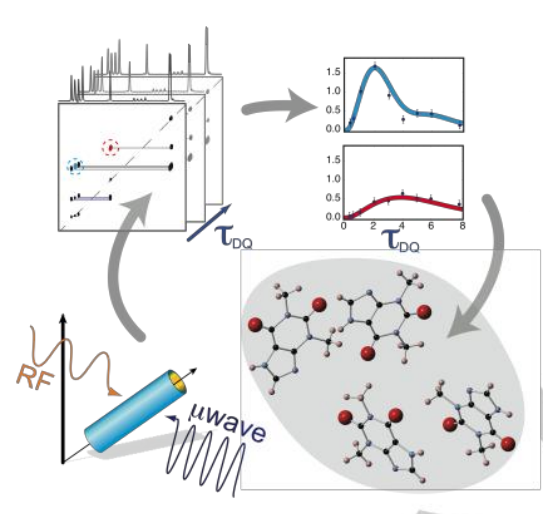

Giulia Mollica, Myriam Dekhil, Fabio Ziarelli, Pierre Thureau, ${ }^{*}$ and Stéphane Viel* $^{*}$

Page No. - Page No.

Quantitative structural constraints for organic powders at natural abundance via dynamic nuclear polarization solid-state NMR 